\title{
Principales medidas de gasto público en Colombia adoptadas en el estado de emergencia económica, social y ecológica implementado por el Decreto Legislativo 417 de 2020
}

Main public expenditure measures in Colombia derived from the state of economic, social and ecological emergency implemented by the Legislative Decree 417 of 2020

Principais medidas de despesas públicas na Colômbia provenientes do estado de emergência econômica, social e ecológica implementadas pelo Decreto-Legislativo 417 de 2020 


\title{
Resumen
}

El presente artículo analiza, desde una perspectiva jurídica y constitucional, las principales medidas sobre gasto público adoptadas por el Gobierno de Colombia para atender el estado de emergencia económica, social y ecológica que generó la pandemia mundial del covid-19, y que se implementó mediante el Decreto 417 de 17 de marzo de 2020.

Palabras clave: gasto público; estado de excepción; solidaridad; covid-19; legislador extraordinario.

\begin{abstract}
This paper aims to describe and analyze from a legal and constitutional perspective, the main measures on public expenditure adopted by the national government of Colombia to approach the state of emergency that caused the global Covid-19 pandemic, implemented by the Decree 417 of March 17, 2020.
\end{abstract}

Key words: Public expenditure; state of emergency; solidarity; covid-19; extraordinary legislator.

\section{Resumo}

Este artigo de pesquisa tem como objetivo descrever e analisar, do ponto de vista jurídico e constitucional, as principais medidas de Despesas Públicas adotadas pelo Governo Nacional da Colômbia para enfrentar o Estado de Emergência Econômica, Social e Ecológica que gerou a pandemia global de Covid-19, e que foi implementado pelo Decreto 417 de 17 de março de 2020.

Palavras chave: Despesa pública; estado de exceção; solidariedade; covid-19, legislador extraordinário. 


\section{Introducción}

El 17 de marzo de 2020 se decretó en Colombia el estado de emergencia económica, social y ecológica, y el Gobierno nacional estableció aislamiento preventivo obligatorio a partir del 25 de marzo ${ }^{1}$. Sectores económicos pararon su actividad productora de renta y la economía del país entró en recesión ${ }^{2}$. En este sentido, el desempleo aumentó ${ }^{3}$ y los ingresos en los hogares disminuyeron, lo que llevó a que aumentaran las necesidades básicas insatisfechas (NBI) de la población, y, en esta medida, fue necesaria la intervención del Estado a través del gasto público para atender los frentes prioritarios y superar la actual situación de salubridad.

De acuerdo con esto, el presente artículo tiene como objetivo realizar un análisis jurídico de las medidas de gasto público que el Gobierno nacional ha implementado en el marco del estado de emergencia económica, social y ecológica del Decreto Legislativo 417 de 17 de marzo de 2020. Para lo anterior, se explicarán algunos presupuestos constitucionales que orientan la actividad del Ejecutivo como legislador extraordinario, específicamente, la relación de los principios de solidaridad, priorización y legalidad con el gasto público. Así mismo, se da cuenta de las medidas relacionadas con este:

- Creación del Fondo de Mitigación de Emergencias (FOME).

- Cambio en el rumbo de las rentas con destinación específica de carácter legal de las entidades territoriales para atender las consecuencias del Covid-19.

- Fortalecimiento patrimonial del Fondo Nacional de Garantías (FNG).

- Creación de la subcuenta para la Mitigación de Emergencias-Covid-19 en el Fondo Nacional de Gestión del Riesgo de Desastres.

- Adquisición obligatoria de títulos de solidaridad (TSD) a los establecimientos de crédito.

- Autorización de otorgamiento de créditos a las empresas de servicios públicos por parte de Findeter.

- Facultad de préstamos a Bancoldex por parte de findeter para que financie proyectos relacionados con la crisis en sectores elegibles.

- Autorización a gobiernos territoriales para modificar el presupuesto según las necesidades de la pandemia.

- Financiación del sistema de transporte masivo a través de créditos.

1 Establecido mediante el Decreto 457 del 22 de marzo de 2020 del Ministerio del Interior.

2 En concordancia con el informe The economy in the time of Covid-19 del Banco Mundial (2020), se estima que el producto interno bruto (PIB) de Colombia para el 2020 disminuya en $2 \%$ debido a las consecuencias de la pandemia del covid-19.

3 De acuerdo con Fedesarrollo (2020), se espera que a mediano plazo la tasa de desempleo aumente en un $4,9 \%$ frente al promedio de 2019. 


\section{Contexto constitucional de las medidas del gasto público en los estados de excepción}

En estados de excepción, el Ejecutivo cuenta con potestades extraordinarias, una de ellas es la posibilidad de asignar el gasto público bajo unos parámetros de orden constitucional que buscan orientar esta actuación y proteger la configuración del Estado social de derecho; en este contexto, para el desarrollo del presente escrito nos basaremos en aquellos principios que a nuestro juicio revisten una importancia especial debido a la aplicación práctica que se analiza en la segunda parte.

De acuerdo con esto, a continuación se procederá a establecer la conexión y relevancia del principio de solidaridad, así como la priorización y legalidad del gasto público en el marco de un estado de excepción.

\section{A. Principio de solidaridad como presupuesto del gasto público}

La solidaridad es uno de los cimientos esenciales de un Estado social de derecho ${ }^{4}$, ya que, como lo afirmó Aristóteles (1988) en su famosa frase "El hombre es un ser social por naturaleza" (p. 50), el humano es incapaz de subsistir sin sus iguales, y, por tanto, debe convivir en sociedad bajo una serie de deberes y obligaciones que mantienen el equilibrio de estas relaciones.

En este sentido, en la Constitución Política de 1991, la solidaridad es concebida en el artículo 1 como un principio fundamental del Estado social de derecho bajo el cual se busca respetar la dignidad humana 5 , y a su vez, es un deber de conducta en donde las personas y los ciudadanos tienen que actuar de manera humanitaria frente a circunstancias que amenacen la vida y la salud de los demás ${ }^{6}$. De igual modo, cuando se refiere a la propiedad privada, el artículo 58 de este texto normativo aclara que tiene una función social y que cuando hay enfrentamiento de derechos prevalece el interés público sobre el privado.

Al respecto, la Corte Constitucional, en Sentencia C-459 de 20047 , afirmó que la solidaridad tiene una doble dimensión: en el Estado y en las personas que hacen parte del conglomerado social; lo cual implica deberes en cada uno; frente al primero, como se mencionó, es uno de los pilares del Estado social del derecho que guía el marco de

4 El profesor Fernández (2012) afirma que "la solidaridad, conjuntamente con la libertad, la igualdad y la justicia, han venido a conformar la que creo que bien podría tildarse de tetralogía axiológica del Estado social de nuestro tiempo".

5 Frente a este punto, Cañón (2017) menciona lo siguiente: "De manera que dentro de la esencia misma de la organización política adoptada por la Carta Fundamental para la sociedad colombiana, aparece incorporado el principio de la solidaridad que debe existir entre sus miembros, sin que este afecte la individualidad de cada uno de ellos, para garantizar el respeto a la dignidad humana, que es propia de cada uno de sus componentes".

$6 \quad$ Numeral 2 del artículo 965 de la Constitución Política de 1991.

7 Otras sentencias en donde la Corte Constitucional abarca el principio de solidaria como un deber exigible a los habitantes del país son: C-767 de 16 de octubre de 2014 y T-517 de 7 julio de 2006. 
cumplimiento de sus fines esenciales, y en el segundo, se materializa a través de las obligaciones que impone la ley:

En esta dimensión el principio de la solidaridad se despliega como un deber que pesa en cabeza del Estado y de todos los habitantes del país. Yendo en el primer caso de lo público hacia lo privado, a tiempo que en el segundo del núcleo familiar hacia el ámbito social, en una suerte de concatenaciones dialécticas que deben tener siempre a la persona como razón y fin último. El deber de solidaridad en cabeza del Estado Social de Derecho es inherente a su existencia y cualificación en la esfera de cumplimiento de sus fines esenciales, al paso que en cabeza de los particulares el deber de solidaridad es exigible en los términos de ley.

A su vez, el Alto Tribunal Constitucional, a través de la Sentencia T-125 de 1994, estableció que en el marco de un Estado social de derecho el principio de solidaridad es un criterio de interpretación constitucional ${ }^{8}$ para la protección de derechos fundamentales por parte del juez de tutela, así como una pauta de comportamiento en sociedad para las personas, sobre el cual se establece la concordancia de sus acciones u omisiones con la ley:

La solidaridad ha dejado de ser únicamente un precepto ético y reviste, en el Estado social de derecho, un valor hermenéutico de primer orden en cuanto a la sujeción de los particulares a la Constitución y a la ley. La eficacia de los derechos fundamentales frente a terceros sujeta al examen constitucional las actuaciones u omisiones de los particulares en los casos determinados por la ley. La solidaridad como modelo de conducta social permite al juez de tutela determinar la conformidad de las acciones u omisiones particulares según un referente objetivo, con miras a la protección efectiva de los derechos fundamentales.

En concordancia con lo expuesto, desde un punto de vista jurídico, la solidaridad es un principio previsto en la Constitución Política del cual se derivan obligaciones en cabeza del Estado y de los ciudadanos, específicamente, ha sido calificado por la jurisprudencia constitucional como un criterio de interpretación en virtud del cual se garantiza la protección de derechos fundamentales.

De lo anterior se desprende que este principio irradia todo el sistema jurídico y el accionar del Estado, lo cual implica que el gasto público tiene una fuerte influencia de la solidaridad en el sentido en que todos los ciudadanos deben contribuir a la financiación de las cargas públicas en épocas de normalidad y, sobre todo, de crisis, ya que en estos

8 Acerca de la Solidaridad desde una perspectiva hermenéutica y bajo el desarrollo jurisprudencial constitucional, Mora afirma que "se aprecia con esto que la fuerza jurídica de la solidaridad, al estar calificada como principio fundante del Estado colombiano, se traduce en un criterio de interpretación constitucional expansivo y presente, que exige del juez constitucional tomarlo en consideración como un aspecto relevante para la resolución de casos concretos" (2012, p. 45). 
tiempos es cuando prevalece el interés general sobre el particular ${ }^{9}$; además, orienta la forma en que deben invertirse los recursos públicos por ser el fundamento para brindar apoyo a los conciudadanos que se encuentren en debilidad manifiesta, y que por ende más lo necesiten (Sentencia T-507 de 5 de julio de 2007) .

\section{B. Priorización del gasto público social}

Un factor determinante a la hora de establecer la asignación del gasto público es la priorización, los ingresos son limitados y es necesario fijar criterios ${ }^{10}$ acordes a las finalidades constitucionales para proteger derechos y principios fundantes de nuestro ordenamiento jurídico; en este sentido, la Constitución Política, en el artículo 334, encarga la dirección de la economía al Estado y le permite intervenir, entre otras cosas, para mejorar la calidad de vida de los ciudadanos; además, expresamente establece que el gasto público social ${ }^{11}$ tiene carácter preferente, esta última premisa también la dispone en los artículos 350 y 366.

En este contexto, la Corte Constitucional ha reiterado la importancia de la priorización del gasto público en varias providencias ${ }^{12}$, en donde afirma que partiendo de la configuración del Estado como social de derecho y ser este el soporte social y económico de la población, es imperante que proteja a través de los ingresos públicos necesidades básicas insatisfechas (Rojas, 2013).

Ahora bien, el mandato constitucional de la priorización del gasto público social sobre las demás asignaciones es una pauta obligatoria que el legislador ordinario debe aplicar al sistema presupuestal y de planeación en favor de solventar las mencionadas necesidades básicas insatisfechas, pero del mismo modo, en los estados de excepción, en donde el Ejecutivo por circunstancias especiales debe regular a través de decretos legislativos, este criterio se vuelve indispensable y requiere mayor atención en la medida en que situaciones

9 Sentencia C-870 de 30 de septiembre de 2003, bajo la cual el Alto Tribunal Constitucional establece que los derechos de propiedad y libertad económica no son absolutos y encuentran sus límites en el interés social establecido en la ley bajo parámetros de igualdad.

10 En la Sentencia T-717 de 2006, el Alto Tribunal Constitucional analiza la posibilidad de ejecutar una partida presupuestal a través de la acción de tutela: "Se ha considerado improcedente que el juez imponga a la Administración el desembolso forzado e inmediato de partidas asignadas en el presupuesto de gastos, porque ello supondría coartar el espacio de discrecionalidad que la Constitución y la ley le confieren al ejecutivo para ejecutar el presupuesto, teniendo en cuenta que en tal operación intervienen variables determinantes como la priorización del gasto público y la disponibilidad de recursos, es decir, razones de oportunidad y conveniencia que inciden en el desembolso de apropiaciones fiscales" (énfasis agregado).

11 El artículo 41 del Decreto 111 de 1996 (Estatuto Orgánico de Presupuesto), define el gasto público social como: "Aquel cuyo objetivo es la solución de las necesidades básicas insatisfechas de salud, educación, saneamiento ambiental, agua potable, vivienda, y las tendientes al bienestar general y al mejoramiento de la calidad de vida de la población, programados tanto en funcionamiento como en inversión".

12 Sentencias constitucionales: C-337 de 19 de agosto de 1993, C-547 de 1 de diciembre de 1994, C-541 de 23 de noviembre 1995, C-015 de 23 de enero 1996 y C-1046 de 4 de octubre de 2001. 
inusuales impiden el normal funcionamiento de la institucionalidad, y generan una vulneración mayor a esos mínimos que el aparato estatal debe proteger y garantizar. ${ }^{13}$

\section{El presupuesto general de la nación y la potestad del Ejecutivo en los estados de excepción}

La herramienta jurídica asignada constitucionalmente para destinar los recursos públicos es el presupuesto de gasto, el cual debe ser decretado por el Congreso, las asambleas departamentales o los concejos distritales y municipales en concordancia con el artículo 345 de la norma superior ya que, de acuerdo con el principio fundante de la democracia, este debe pasar por un debate en instancias que representen la voluntad de los ciudadanos.

Así pues, de las disposiciones constitucionales contempladas en los artículos 346 y 347 se desprende que el presupuesto se rige por un principio de legalidad en virtud del cual no se puede hacer erogación, gasto público o transferencia de créditos que no se encuentren debidamente soportados en la ley, y que, en palabras de la Corte Constitucional en sentencia C-442 de 4 de mayo de 2001, se proyecta en una dimensión de especialidad que actúa como un control político al Ejecutivo:

El principio de legalidad del gasto no se limita a determinar que el Congreso debe aprobar el total del gasto que se ejecutará en la vigencia presupuestal respectiva, sino que en las democracias contemporáneas en virtud de tal principio el legislativo indica también la manera en la cual dicho gasto total estará repartido entre los distintos órganos del Estado, con lo cual se facilita de mejor modo el control político económico sobre el ejecutivo a que se ha aludido. Es decir, el Parlamento autoriza de manera especializada, por capítulos, la ejecución del gasto. Por ello, los traslados presupuestales también deben ser previamente autorizados por el legislador, como lo dispone el inciso segundo del artículo 345 de la Carta Política cuando indica que no se podrá "transferir crédito alguno a objeto no previsto en el respectivo presupuesto". Esta faceta del principio de legalidad ha sido llamada principio de especialización del gasto público, e impide al Gobierno destinar una partida presupuestal a un objeto distinto del señalado en la ley anual de presupuesto. (Énfasis agregado).

Ahora bien, lo dicho hasta el momento parte del supuesto de que nos encontremos en tiempos de paz o normalidad; sin embargo, en los estados de excepción el Ejecutivo actúa como legislador extraordinario para decretar medidas tendientes a contrarrestar las circunstancias que dieron lugar a esa excepcionalidad, debido a que la institucionalidad y el ordenamiento jurídico ordinario no son suficientes para solventar esos problemas.

13 Esta afirmación fue validada por la Corte Constitucional en la Sentencia C-700 de 18 de noviembre de 2015, en donde se suspende una norma del ordenamiento jurídico ordinario que no permite la priorización del gasto en un estado de emergencia económica y social. 
En consonancia con esto, el Estatuto Orgánico del Presupuesto y la Ley Estatutaria de Estados de Excepción, en el artículo 83 y en el literal LL del parágrafo 5 del artículo 38 respectivamente, disponen que en esta situación el Gobierno podrá modificar y realizar operaciones presupuestales conexas a la crisis.

Bajo este razonamiento, en resumen, el Alto Tribunal Constitucional, en Sentencia C-434 de 12 de julio de 2017 sostiene que, en principio, el poder de establecer el presupuesto lo regentan los órganos de representación popular, sin embargo, en los estados de excepción el Ejecutivo actúa como legislador transitorio en esta materia, de manera tal que puede realizar los cambios presupuestales necesarios para atender los tiempos excepcionales:

De este modo, la Corte ha considerado que rige el principio de legalidad del presupuesto o la reserva de ley para su expedición, modificación o adición, en virtud de la trascendencia del principio democrático en la adopción de las decisiones sobre el uso y destinación de los recursos públicos. Al consagrar los anteriores mandatos, sin embargo, el Constituyente también hizo la salvedad de que las citadas reglas en materia presupuestal tienen aplicación en tiempos de paz o normalidad institucional, de modo que, en estados de excepción, se deja abierta la posibilidad de que otro centro de producción normativa y, en específico, el Ejecutivo, quien en tales situaciones se convierte en legislador transitorio, intervenga el presupuesto general de la Nación, cambie la destinación de algunas rentas, reasigne partidas y realice operaciones presupuestales, con el propósito de destinar recursos para la superación del estado de excepción.

En resumen, del contexto constitucional planteado se desprende que hay una serie de particularidades en lo que se refiere al gasto público y el presupuesto en los estados de excepción, los cuales no son indiferentes al estado de emergencia económica, social y ecológica del Decreto 417 de 17 de marzo de 2020, por tanto, en el siguiente apartado se podrá observar de manera práctica cómo el principio de solidaridad, la priorización y legalidad se concatenan sistemáticamente en las medidas decretadas por el Gobierno nacional en esta materia.

\section{Análisis de las medidas sobre gasto público decretadas por el Gobierno nacional de Colombia ante la crisis económica, social y ecológica del Decreto Legislativo 417 de 2020}

En este apartado se describirán y analizarán, desde una óptica constitucional, y, sobre todo, bajo los presupuestos mencionados anteriormente, las medidas que ha establecido el Gobierno nacional en el estado de emergencia económica, social y ecológica implementado en el Decreto Legislativo 417 de 17 de marzo de 2020. 


\section{A. Creación del Fondo de Mitigación de Emergencias fome}

El Fondo de Mitigación de Emergencia (FOME) fue creado por el Decreto 444 del 21 de marzo de 2020, tiene por objetivo reorientar rentas para atender efectos negativos en salud, actividad productiva y, en general, desarrollo de la economía en cuanto a empleo y crecimiento, en el marco de la emergencia económica, social y ecológica.

Este fondo está adjudicado al Ministerio de Hacienda, el cual lo administra a través de un portafolio independiente de la Dirección General de Crédito Público y Tesoro Nacional, y deberá realizar todas las operaciones necesarias para su funcionamiento, tales como trámites contractuales, contables, presupuestales que se regirán por el derecho privado.

Además de lo mencionado, el artículo 4 establece que los recursos del FomE deberán dirigirse tanto para atender las consecuencias de la crisis sanitaria, así como evitar su propagación, y concretamente se refiere a los siguientes frentes:

- Financiar de manera complementaria a entidades del Presupuesto General de la Nación que lo requieran ${ }^{14}$.

- Atender los costos que requieran las operaciones necesarias para alcanzar la finalidad del FOME.

- Generar liquidez temporal al sector financiero con operaciones de apoyo ${ }^{15}$, las cuales se materializarán a través de transferencias transitorias de valores, para esto la nación podrá contratar con el Fondo de Reserva para la Estabilización de la Cartera Hipotecaria $(\text { FRECH })^{16}$.

- Auxiliar empresas privadas, públicas o mixtas que desarrollen actividades de interés nacional mediante la inversión de instrumentos de capital o deuda, o proveerles financiamiento directo.

- Proporcionar liquidez a la nación cuando no cuenta con fuentes de financiación ordinarias para atender la crisis.

Por otro lado, la norma regula el régimen de financiación del FOME y establece que los recursos provendrán de las siguientes fuentes:

14 El Decreto Legislativo 559 de 15 de abril de 2020 prevé que algunos de los recursos de la subcuenta de Mitigación del covid-19 provienen de esta fuente de financiamiento.

15 El artículo 9 del Decreto 444 de 21 de marzo de 2020 considera que una operación de apoyo son aquellos depósitos de recursos del FOME a las bancas estatales de primer y segundo piso por un plazo de hasta 12 meses.

16 Fue creado por el artículo 48 de la Ley 546 de 1999 y es administrado por el Banco de la República, tiene como finalidad ayudar a la adquisición de vivienda. 
1. Fondo de ahorro y estabilización(FAE): pertenece al Sistema General de Regalías ${ }^{17}$ y es administrado por el Banco de la República a través del patrimonio autónomo "Fideicomiso FAE", y, como su nombre lo indica, es un ahorro para las entidades territoriales que se utiliza en tiempos de poca abundancia para dinamizar la economía y equilibrar el gasto público.

Ahora bien, el Ministerio de Hacienda Pública podrá pedir al FAE, a título de préstamo, hasta el $80 \%$ de sus recursos en la medida que los vaya necesitando el FOME para enfrentar la crisis; esta operación se deberá realizar a través de pagarés emitidos por la nación $^{18}$, en dólares de Estados Unidos y a una tasa de interés del $0 \%$.

El pago de esta deuda se empezará a realizar en el 2023, por cuotas anuales en dólares de Estados Unidos equivalentes a un billón de pesos a la tasa representativa del mercado al momento del pago, y se hará con cargo al rubro del servicio de la deuda del Presupuesto General de la Nación.

2. Fondo de Pensiones Territoriales (FONPET): fue creado por la Ley 549 de 1999, es un fondo sin personería jurídica gestionado por el Ministerio de Hacienda y Crédito Público, tiene como finalidad administrar, recaudar y asignar los recursos ${ }^{19}$ determinados para atender el pasivo pensional de las entidades territoriales.

En cuanto al fOME, el Ministerio de Hacienda y Crédito Público puede solicitar en préstamo algunos recursos ${ }^{20}$ del FONPET, particularmente, los que provienen del impuesto de timbre nacional, privatizaciones y capitalizaciones que se encuentren sin distribuir a las cuentas individuales de las entidades territoriales.

En igual sentido, en el artículo 14 se establece un "mecanismo residual", mediante el cual se permite que el Ministerio de Hacienda disponga, a título de mutuo, de los otros $^{21}$ recursos del FONPET, cuando se acaben las demás fuentes de financiación de la emergencia económica, social y ecológica del Decreto 417 de 2020, y no se afecte el pago de las obligaciones que este fondo debe cumplir.

17 Ingresos provenientes de la explotación de recursos no renovables, están regulados en la ley (art. 1, Ley 1530 de 2012).

18 Estos pagarés podrán exigirse anticipadamente cuando el FAE los requiera para suplir montos faltantes de desahorro o haya reducción drástica de los recursos (arts. 48 y 55, Ley 1530 de 2012).

19 Algunos recursos provienen del Sistema General de participaciones, impuestos nacionales, Sistema general de Regalías, Capitalizaciones y demás (art. 2, Ley 549 de 1999).

20 Artículo 12 del Decreto Legislativo 444 de 21 de marzo de 2020.

21 Los otros recursos son los que no menciona el artículo 12 del Decreto Legislativo 444 de 21 de marzo de 2020 y se encuentran en el artículo 2 de la Ley 549 de 1999. 
Hay que mencionar, además, que el Ministerio podrá utilizar como fuente de pago de las deudas que adquiera, los recursos provenientes de la nación que son destinados al FONPET en las vigencias 2020, 2021 y 2022, los cuales deberán ingresar al FOME y de ahí realizar la respectiva operación de crédito.

Respecto a las obligaciones mencionadas anteriormente, es necesario precisar que estos valores deberán pagarse máximo dentro de los 10 años siguientes al momento del desembolso, y se harán con cargo al rubro del servicio a la deuda del Presupuesto General de la Nación.

3. Recursos asignados en el Presupuesto General de la Nación: bajo esta posibilidad, el Gobierno nacional puede asignar recursos al FOME a través de la Ley anual de presupuesto, la cual es un instrumento jurídico del sistema presupuestal que permite dar cumplimiento a los planes y programas de desarrollo económico y social ${ }^{22}$.

4. Rendimientos financieros generados por la administración de recursos: como se mencionó, el FOME es administrado en un portafolio independiente por la Dirección General de Crédito Público y Tesoro Nacional del Ministerio de Hacienda y Crédito Público, en este sentido, las utilidades o ganancias derivadas de las inversiones u operaciones que se realicen con los recursos de este fondo serán una fuente de su financiación.

5. Los demás que determine el Gobierno nacional: esta fuente podría asimilarse a una "cláusula abierta" en la medida que autoriza al Gobierno nacional, según su criterio y la necesidad de recursos para atender la crisis sanitaria, asignar recursos al FOME.

6. Fondo de Riesgos Laborales: fue establecido por el artículo 87 del Decreto 1295 de 22 de junio de 1994, hace parte del Sistema General de Riesgos profesionales, está adscrito al Ministerio de Trabajo y Seguridad Social y es administrado por encargo fiduciario, tiene varios objetivos relacionados con accidentes y enfermedades laborales ${ }^{23}$.

Este fondo fue incluido como una fuente de financiación del FOME a través del Decreto Legislativo 552 de 2020, el cual establece que el Ministerio de Hacienda puede solicitarle un monto máximo del $80 \%$ del saldo acumulado ${ }^{24}$ en la medida que los vaya requiriendo. Establece que esta operación se concretará mediante pagarés a una tasa de interés del $0 \%$, y que el cumplimiento de esta deuda se realizará dentro de las 10

22 Artículo 10 del Decreto 111 de 15 de enero 1996.

23 El artículo 88 del Decreto Ley 1295 de 1994 los establece de manera precisa, pero el principal es realizar estudios e investigaciones relacionados con la promoción y prevención de los accidentes y enfermedades laborales.

24 El propio Decreto Legislativo 552 de 2020, en la parte de los considerandos, afirma que desde la creación hasta 31 de marzo de 2020, el saldo acumulado del Fondo de Riesgos Laborales es de \$412.666.165.790. 
vigencias fiscales siguientes al primer desembolso, con cargo al rubro del servicio a la deuda del Presupuesto General de la Nación. ${ }^{25}$

Por lo que se refiere a este punto, hay un problema de exequibilidad, ya que este decreto legislativo no cumple con el requisito material de no contradicción específica. La Constitución Política, en el artículo 48, de manera expresa prohíbe "la destinación o utilización de los recursos de las instituciones de la Seguridad Social para fines diferentes a ella", y no hace ningún tipo de excepción por cuanto es un servicio público de carácter obligatorio ${ }^{26}$.

Sobre la Constitucionalidad del Decreto Legislativo 444 de 21 de marzo de 2020, la Corte Constitucional se manifestó a través de comunicado de prensa número 26 del 24 y 25 de junio de 2020, en donde informa que a través de la Sentencia C-194 de 2020 declara exequible la mencionada norma por cumplir con los requisitos formales y materiales, en atención especial a la no vulneración de las disposiciones de la norma superior respectivas a autonomía territorial del artículo 287 y ejercicio del control fiscal por parte de la Contraloría, artículo 297.

Es preciso aclarar que estoy de acuerdo con la decisión del Alto Tribunal Constitucional, la cuestión es que estos recursos se deben implementar siempre en el marco de la emergencia económica, social y ecológica bajo los criterios de priorización ${ }^{27}$ del gasto público, por cuanto es un pilar de la planeación fiscal tanto en tiempos ordinarios como de crisis.

Por su parte, los decretos legislativos que se relacionan en la tabla 1 adicionan las siguientes cifras al FOME:

Tabla 1. Decretos legislativos de adiciones al fome

\begin{tabular}{|c|c|l|c|c|}
\hline No. & Decreto & \multicolumn{1}{|c|}{ Fecha } & Cifra & Constitucionalidad \\
\hline 1 & 519 & Abril 5 de 2020 & $\$ 15.100 .000 .000 .000$ & C- $170 / 20$ \\
\hline 2 & 571 & Abril 15 de 2020 & $\$ 329,000,000,000$ & C-215/20 \\
\hline 3 & 572 & Abril 15 de 2020 & $\$ 9,811,300,000,000$ & C-206/20 \\
\hline
\end{tabular}

Fuente: elaboración propia.

25 Tal y como se dispuso respecto del FAE, los pagarés se podrán materializar parcialmente de manera anticipada cuando el Fondo de Riesgos Laborales con certificación del Ministerio de Trabajo y Seguridad Social, los necesite para atender sus obligaciones.

26 Algunas sentencias de la Corte Constitucional que sustentan esta posición son: T-481 de 2 de mayo de 2000 y C-174 de 16 de julio de 2008.

27 El Departamento de Derecho Fiscal, junto al de Derecho Constitucional de la Universidad Externado de Colombia, en Concepto de constitucionalidad, alegan que la exequibilidad de este decreto debe estar condicionada a que se establezca de manera clara el destino de los recursos y la definición de empresas de interés nacional que incluyan a las Mipymes, porque de lo contrario no hay priorización del gasto público social y se vulnera el derecho de igualdad. 


\section{B. Reorientación de rentas con destinación específica}

A través del artículo 1 del Decreto Legislativo 461 de 22 de marzo de 2020 se faculta a la rama ejecutiva local -alcaldes y gobernadores- para cambiar la destinación específica de rentas de sus territorios desde que tengan como objetivo establecer medidas dirigidas a combatir las causas de la declaratoria del estado de emergencia económica, social y ecológica, salvo las establecidas de manera directa por la Constitución Política.

En condiciones ordinarias, este tipo de operaciones presupuestarias deben ser aprobadas por los órganos locales de representación popular, concejos municipales y asambleas departamentales, bajo iniciativa de alcaldes y gobernadores respectivamente, ya que en virtud del principio constitucional democrático y la legalidad del gasto (Sentencia C-685 de 5 de diciembre de 1996) es necesario que sean discutidos y autorizados en estos espacios, y en caso de que se requiera mediación alguna, es necesario que sea efectuada por este mismo medio.

En este sentido, esta medida fue establecida debido a la necesidad de poner a disposición una herramienta para que los entes territoriales, de manera directa, puedan ejecutar presupuestos para hacer frente a las consecuencias de la pandemia, teniendo en cuenta que ellos son los que conocen de primera mano las necesidades de su territorio, y, por tanto, podrán decidir la manera correcta y eficiente de ejecutar el gasto público en una situación excepcional de crisis que requiere atención inmediata.

Es importante aclarar que los alcaldes y gobernadores, en virtud de esta autorización, solo pueden dirigir estas rentas de destinación específica a esas problemáticas que se originaron en el marco del Estado de Emergencia, tal y como lo afirma el parágrafo 1 del artículo primero del decreto mencionado.

Por otro lado, el artículo 6 del Decreto Legislativo 571 del 15 de abril de 2020, permite la destinación a la atención de las consecuencias de la emergencia económica, social y ecológica de los ingresos y rentas del:

- Presupuesto General de la Nacional.

- Presupuesto de establecimientos públicos del orden nacional.

- Fondos especiales.

- Contribuciones parafiscales.

Como se afirmó anteriormente, la norma está facultando al Ejecutivo a redirigir rentas que tenían decidida su ruta con anterioridad, a conjurar la crisis sanitaria; a este efecto aplica lo explicado hasta el momento, y vale puntualizar que esa disposición no aplica para las destinaciones de carácter constitucional, así como que estos recursos tienen que ser utilizados en el marco del Estado de Emergencia.

Finalmente, la Corte Constitucional, mediante comunicado 24 del 10 y 11 de junio de 2020, anunció que declararía la exequibilidad de la norma sub examine por medio de 
Sentencia C-169 de 2020, por cuanto se ajusta a los requisitos formales y materiales del juicio de constitucionalidad de los decretos legislativos.

\section{Fortalecimiento económico del Fondo Nacional de Garantías}

El Decreto Legislativo 492 de 28 de marzo de 2020 tiene como objetivo fortalecer económicamente el Fondo Nacional de Garantías (FNG), el cual, en el marco de la crisis sanitaria, tiene como función respaldar la adquisición de créditos de personas naturales y jurídicas afectadas económicamente por la pandemia del covid-19.

Con el propósito de cumplir con este objetivo, el Decreto en mención dispone que las fuentes de financiación del FNG son:

i. Excedentes de capital y dividendos de entidades estatales pertenecientes a la Rama Ejecutiva nacional en los montos autorizados (art. 4).

ii. Hasta $\$ 2,6$ billones de pesos de la enajenación de participación accionaria del Estado en el Fondo para Intervenciones ante la Ocurrencia de Desastres Naturales (FONDES) no incorporados en el Presupuesto General de la Nación.

En este contexto, respecto de la primera fuente de recursos, se estableció el traslado de la propiedad de las empresas de la Rama Ejecutiva sujetas a vigilancia por la Superintendencia financiera o que desarrollen actividades conexas al servicio financiero, del orden nacional, en cabeza del Ministerio de Hacienda y Crédito Público para que aporte las acciones de estas entidades al Grupo Bicentenario S.A.S, y así finalmente este sea el encargado de hacer los traslados autorizados al FNG, a través de la figura de reducción de capital.

En consonancia con la motivación de este decreto, el Gobierno nacional alegó en los considerandos que el distanciamiento social obligatorio llevó a que la situación económica del país se viera afectada de manera negativa, de tal manera que las empresas y personas naturales comerciantes se encuentran en una situación de escasez de ingresos, y viendo la necesidad de adquirir créditos para sobrellevar la situación.

Sin embargo, debido a que muchos no cuentan con el respaldo suficiente, se ve la necesidad de fortalecer el FNG y facilitar el proceso de adquisición de crédito de manera eficiente e inmediata, para lo cual se adicionaron recursos a esta entidad con el propósito de aumentar el nivel de operación.

En mi opinión, la simple medida de robustecer el FNG cumple con los requisitos de constitucionalidad de los decretos legislativos expedidos en el marco del estado de emergencia económico, social y ecológico que establece la Norma de normas (art. 215, CP) y la Ley Estatutaria de Estados de Excepción (cap. IV, Ley 137 de 1994).

No obstante lo anterior, es pertinente puntualizar que lo establecido respecto al traslado de la propiedad al Grupo Bicentenario S.A.S de entidades financieras de la Rama Ejecutiva nacional no tiene conexidad interna con el decreto, es decir, sencillamente de manera directa el Ejecutivo pudo autorizar el traslado presupuestario de los recursos. Además, la 
crisis sanitaria no es el espacio legal y constitucional para determinar la estructura de la Administración Pública Nacional, ya que no hay relación con la pandemia del covid-19 y sus efectos.

Por el contrario, la Corte Constitucional difiere de esta postura según lo manifiesta en el comunicado de prensa No. 26 del 24 y 25 de junio de 2020, ya que por medio de la Sentencia C-200 de 2020 declara constitucional el Decreto Legislativo 492 de 2020 y afirma que el fortalecimiento del Grupo Bicentenario S.A.S “asegura la coordinación y centralización de estrategias y recursos, entre las distintas entidades financieras del Estado, para facilitar el crédito y otros productos y servicios a las Mipymes y a los trabajadores independientes".

Por último, el Decreto $522^{28}$ del 15 de abril de 2020 adiciona y ejecuta al Presupuesto General de la Nación de la vigencia 2020 la suma de \$3.250.000.000.000, concretamente, la asigna al Fondo Nacional de Garantías.

\section{Subcuenta para la Mitigación de Emergencias covid-19}

El 15 de abril de 2020, mediante el Decreto Legislativo 559, el Gobierno nacional decidió establecer una subcuenta en el Fondo Nacional de Gestión del Riesgo de Desastres ${ }^{29}$ para la Mitigación de Emergencias del covid-19 por un periodo de dos años; tiene como objetivo financiar la provisión de bienes, servicios y obras necesarios ${ }^{30}$ para atender e impedir la prolongación de las consecuencias negativas de la crisis sanitaria en población en condición de vulnerabilidad y en el sistema de salud. Estas operaciones se rigen por la regulación contractual de privados.

Esta subcuenta se gestiona a través de una junta administradora creada por el artículo 5 del mencionado decreto, compuesta por un gerente y seis representantes escogidos por el presidente de la República, la cual ejecutará sus procesos y tendrá de manera general la función de establecer los lineamientos sobre cómo se invertirán los recursos y cómo se alcanzará el objetivo que se busca cumplir. Es importante aclarar que en este caso el ordenador del gasto es el director de la Unidad Nacional para la Gestión del Riesgo de desastres, es decir que esté último es el único que puede ejecutar presupuestos.

28 En comunicado 27 del 1 y 2 de julio de 2020 la Corte manifiesta que declarará exequible este decreto legislativo mediante Sentencia C-212 de 2020.

29 Creado inicialmente por el artículo 1 del Decreto 1547 de 1984 como el fondo de calamidades, posteriormente la Ley 1523 de 2012 lo incorporó al Sistema Nacional de Gestión de Riesgo de Desastres Naturales y le cambió su denominación en el artículo 47 a Fondo Nacional de Gestión de Riesgo de Desastres; tiene objetivo de interés público, el cual consiste en realizar las gestiones necesarias para implementar y dar continuidad a la política de gestión de riesgo de desastres. Es una cuenta especial de la nación con independencia administrativa, patrimonial, contable y estadística.

30 El artículo 10 del Decreto Legislativo 559 de 15 de abril 2020 autoriza al Fondo la adquisición de bienes y servicios en salud a nivel internacional siempre que se utilicen para atender los efectos del covid-19. 
Frente a los recursos que subvencionan la subcuenta, el decreto legislativo dispone que administrará los que el Ministerio de Hacienda y Crédito Público le transfiera del FOME ${ }^{31}$ y los que procedan de donaciones de carácter nacional e internacional, públicas o privadas y del mismo Fondo Nacional de Gestión de Riesgos de Desastres, estas transferencias a títulos gratuitos se encuentran exentas y no requieren de procedimientos especiales.

Frente a la constitucionalidad del decreto sub examine, la Corte Constitucional, en comunicado de prensa No. 27 del 1 y 2 de julio de 2020 anuncia que lo declarará exequible en la Sentencia C-210 de 220 porque cumple los requisitos de los juicios materiales y de forma, en específico porque tiene relación con la crisis económica, social y ecológica, y el mecanismo de administración dispuesto es el correcto para cumplir con dicha finalidad.

Bajo mi opinión, estas medidas son la materialización de los principales mecanismos con los que cuenta el Gobierno nacional en tiempos excepcionales de crisis: la planeación presupuestaria y reorientación del gasto; además, es importante advertir que aquí se utilizan criterios de priorización del gasto público como la preferencia de la población en situación de vulnerabilidad ${ }^{32}$.

\section{E. Inversión obligatoria en títulos de deuda pública}

Una de las medidas introducidas mediante el Decreto Legislativo 562 del 15 de abril de 2020 por el Gobierno nacional para adquirir liquidez y poder atender la crisis sanitaria fue establecer la adquisición obligatoria de títulos de solidaridad (TDS) para los establecimientos de crédito dentro de los 90 días siguientes a la expedición de la norma.

Los TDS son títulos de deuda pública interna a la orden ${ }^{33}$ y de libre negociación, gestionados mediante administración fiduciaria por el Banco de la República e incluidos presupuestalmente en el FOME. Consisten en una inversión obligatoria que deben realizar los establecimientos de crédito $^{34}$, en la cual el capital se paga al año de la fecha de emisión del título, prorrogable hasta el año 2029, y los intereses de manera anual; esta adquisición

31 En virtud del numeral 1 del artículo 4 del Decreto Legislativo 444 de 21 de marzo de 2020.

32 El Departamento de Derecho Fiscal de la Universidad Externado de Colombia se pronunció frente a la constitucionalidad de este decreto, y considera que es constitucional bajo la condición de que: "(i) no se puede derivar ningún tipo de enriquecimiento o incremento patrimonial a particulares a partir de la utilización de los recursos del FOME de manera arbitraría; (ii) se debe garantizar que la ejecución de los recursos esté sometida a criterios de priorización a los sectores sociales y población más vulnerable y mayormente afectadas por la crisis, (iii) atendiendo a la concreción de criterios objetivos, transparentes y plurales en la realización del gasto, y (iv) que se establezcan controles de vigilancia administrativos y fiscales reforzados, en cabeza de los órganos de control sobre los recursos del FOME la respectiva subcuenta que se crea".

Están exceptuadas las Instituciones Oficiales Especiales (IOE), llamadas “bancos de segundo piso”. 
deberá ser demostrada ante la Superintendencia financiera, y los montos y demás particularidades serán objeto de regulación por el Ejecutivo ${ }^{35}$.

En lo que se refiere a la constitucionalidad del Decreto analizado, el Alto Tribunal Constitucional, en el comunicado de prensa No. 26 del 24 y 25 de junio de 2020, establece la exequibilidad mediante Sentencia futura C-196 de 2020, argumenta que, si bien encuentra una vulneración de los derechos a la libre empresa y a la propiedad, esta es necesaria y proporcional por cuanto prevalece el interés general en concordancia con la gravedad de la emergencia económica, social y ecológica.

\section{F. Financiación de las Empresas de Servicios Públicos Domiciliarios a través de Findeter}

El objetivo del Decreto 581 del 15 de abril de 2020 es generar liquidez a las Empresas de Servicios Públicos Domiciliarios a fin de que puedan dar cumplimiento a las medidas dispuestas para atender los efectos de la crisis sanitaria ${ }^{36}$, para esto autoriza que la Financiera de Desarrollo Territorial (Findeter) ${ }^{37}$ le otorgue créditos directos hasta el 31 de diciembre de 2020.

Los montos de estos créditos los deberá establecer el Ministerio de Minas y Energía, el Ministerio de Vivienda, Ciudad y Territorio o la Superintendencia de Servicios Públicos de acuerdo con los periodos en que las Empresas de Servicios Públicos acepten pagos diferidos en concordancia con los decretos legislativos expedidos por el Gobierno nacional. Por otro lado, Findeter deberá regular las condiciones generales de esta financiación.

Estas operaciones podrán ser garantizadas por el FNG o por las entidades territoriales, con la simple autorización del gobernador o alcalde según corresponda, para este efecto se podrán emplear los recursos provenientes del Sistema General de Participaciones destinados a los servicios públicos de agua potable y saneamiento.

Por último, los recursos que utilizará Findeter para esta operación provendrán del FOME en la medida que la Dirección de Crédito Público y Tesoro Nacional del Ministerio de Hacienda invertirá en instrumentos de deudas emitidos por esta a un plazo de 40 meses, renovable por una vez hasta por 12 meses, a una tasa de remuneración del $0 \%$.

A la fecha, la Corte Constitucional no se ha pronunciado sobre la exequibilidad de esta norma, sin embargo, a mi juicio este decreto cumple con los criterios que establecen la norma superior y la LEEE bajo el entendido de que estos créditos se otorguen a las Empresas

35 El artículo 3 del decreto analizado regula los porcentajes máximos de inversión obligatoria, y el Decreto Reglamentario 685 de 2020 ordena la emisión de los TDS.

36 Algunas de estas medidas son el pago diferido de servicios públicos de estratos 1 y 2 de los Decretos 528 de 7 de abril de 2020 y 517 de 15 de abril de 2020.

37 Es una sociedad de economía mixta creada por la Ley 57 de 1989 que funge como la "Banca de Desarrollo que ofrece soluciones integrales para construir territorios sostenibles a través de la planeación, estructuración, financiación y asistencia técnica de proyectos de infraestructura, que mejoran la calidad de vida de los colombianos" (Findeter.gov, 2020). 
de Servicios Públicos afectadas por la crisis económica, social y ecológica; en otras palabras, si la falta de liquidez encuentra su origen en una causa diferente a la pandemia, el Gobierno deberá actuar a través del ordenamiento jurídico ordinario y no mediante decretos legislativos ${ }^{38}$.

\section{G. Autorización de operaciones financieras a Findeter y Bancoldex}

El Ejecutivo, mediante Decreto Legislativo 468 del 23 de marzo de 2020, crea líneas de crédito directo con tasa compensada en la Financiera de Desarrollo Territorial (Findeter) y el Banco de Comercio Exterior de Colombia (Bancoldex ${ }^{39}$, por cuanto autoriza que estas entidades financien proyectos y actividades en sectores concretos o elegibles para atender los efectos negativos de la crisis económica, social y ecológica.

En igual sentido, le permite a Findeter el otorgamiento excepcional de créditos con tasa compensada o créditos sindicados para la financiación también de proyectos y actividades en sectores concretos o elegibles para atender la crisis sanitaria, con entidades de derecho internacional público, las cuales, bajo criterios de priorización, se deben otorgar a municipios categorías 4, 5 y 6; departamentos 2,3 y 4, y distritos, que deben contar con viabilidad financiera y técnica.

Acerca de la constitucionalidad de esta norma, la Corte Constitucional, mediante Sentencia C-160 de 3 de junio de 2020 la declaró exequible por tres razones: i) tienen como propósito evitar la propagación de la crisis y atender sus consecuencias negativas; ii) las medidas ayudan a sistematizar disposiciones constitucionales como la dirección de la economía por parte del Estado (art. 334), regulación legislativa financiera (art. 150) y el endeudamiento público (art. 364); iii) son medidas razonables y proporcionables.

Estoy de acuerdo con el análisis del Alto Tribunal Constitucional, estas medidas, además de cumplir con los requisitos formales y materiales del juicio de constitucionalidad, son la expresión de uno de los campos de acción con los que cuenta el Ejecutivo para actuar en momentos de crisis, ya que permiten la regulación y disposición de recursos a través de mecanismos como el endeudamiento público para redirigir rentas a los sectores más afectados.

38 Los departamentos de Derecho Fiscal y Constitucional de la Universidad Externado de Colombia se pronunciaron sobre la constitucionalidad de este decreto en concepto conjunto, alegando que es condicionada desde que estos créditos se otorguen en el marco de los decretos 441, 517, 518 y 589 de 2020 , pero que, además, se implementen criterios de priorización de acuerdo con las necesidades e impacto en la sociedad. Por otro lado, piden la inconstitucionalidad del artículo 2, numeral 3 por no cumplir con los requisitos de los juicios de conexidad, motivación suficiente y necesidad.

39 De acuerdo con el artículo 42 del Decreto 1159 de 1999, Bancoldex está adscrito al Ministerio de Comercio Exterior, es una sociedad anónima de económica mixta organizada como establecimiento de crédito bancario, que tiene por objetivo promocionar las exportaciones (art. 21, Ley 7 de 1991). 


\section{H. Presupuestos territoriales}

Una de las medidas implementadas por el Gobierno nacional en el marco del estado de emergencia económica, social y ecológica fue autorizar a los gobernadores y alcaldes a realizar las modificaciones al presupuesto que bajo su autonomía consideren necesarias para atender los efectos de la pandemia.

Por lo que se refiere a la constitucionalidad de este decreto, la Corte Constitucional, en Comunicado de prensa No. 25 del 17 y 18 de junio de 2020 anunció la exequibilidad en la Sentencia C-178 de 2020, argumentando que, además de cumplir con los juicios de constitucionalidad, estas medidas se encuentran amparadas por los principios de celeridad y eficacia del artículo 209 superior.

Frente a este punto, es importante aclarar que el Presupuesto es un mecanismo jurídico del sistema presupuestario mediante el cual el Poder Ejecutivo puede orientar el gasto de acuerdo con el plan de gobierno y las necesidades de la población, por tanto, en épocas extraordinarias de crisis que requieren una inversión imprevista y mayor a la esperada, se vuelve imperativo la autorización de su modificación de manera transitoria sin la aprobación de los órganos de representación popular por cuanto se necesita actuar de manera pronta y eficiente.

\section{Financiación del Sistema de Transporte Masivo}

Con la finalidad de otorgar recursos al Sistema de Transporte Masivo, el Decreto 575 del 15 de abril de 2020 permite la adquisición de créditos por parte de sus gestores con respaldo del FNG; asimismo, autoriza que los entes territoriales realicen este tipo de operaciones y que incluso los garantice la nación, bajo la condición de obtener autorización del Ministerio de Hacienda y Crédito Público mediante resolución.

Por otro lado, autoriza que el Fondo Nacional de Modernización del Parque Automotor de Carga (FOMPACARGA) tramite convenios con Bancoldex para que otorguen créditos a personas naturales y jurídicas en relación con el servicio público de transporte; para este efecto dispone la reorientación a este fondo de \$5.000.000.000 del Presupuesto General de la Nación.

Acerca de la constitucionalidad de este decreto legislativo, la Corte Constitucional no se ha pronunciado al respecto; sin embargo, es factible afirmar que los apartados analizados de la norma son exequibles bajo la condición de que tanto la financiación del sistema como de las personas naturales y jurídicas surja en virtud de los efectos negativos de la pandemia.

\section{Conclusiones}

Los estados de excepción son una figura jurídica excepcional implementada en la Constitución Política que aplica en tiempos de crisis, en virtud de la cual se le atribuyen potestades 
excepcionales al Ejecutivo para que actúe y supere las circunstancias problemáticas que lo originaron; es por esto que se le llama legislador extraordinario, y un gran frente que se debe atender bajo esta perspectiva es la orientación del gasto público.

Bajo este contexto, la asignación del gasto público se enmarca bajo las premisas constitucionales del principio de solidaridad, la priorización y la legalidad, que están dirigidas a proteger la configuración del Estado y salvaguardar los derechos de los ciudadanos, las cuales deben ser atendidas por el Ejecutivo en tiempos excepcionales, en donde sus competencias se amplían y se puede visualizar cómo interactúan y se complementan entra ellas.

El primero, la solidaridad, es un principio fundante del Estado social de derecho que parte de la base de que la convivencia dentro de una sociedad exige acatar una serie de deberes que permitan un fluir armónico de las relaciones tanto en cabeza del Estado como de las personas, en cuanto deben actuar ayudando a otros que se encuentren en situaciones que arriesguen la salud o la vida.

La Corte Constitucional le ha dado el alcance de valor hermenéutico a este principio, lo que significa que es un criterio para establecer si una conducta del Estado o de los habitantes del territorio nacional es conforme a la ley, con lo cual se protegen y garantizan derechos fundamentales. Bajo la perspectiva del gasto público, los ciudadanos deben contribuir al financiamiento de las cargas estatales para que se dé cumplimiento a los fines esenciales, lo cual resulta relevante en épocas de crisis por cuanto dirige la forma en que se invierten los recursos cuando no funciona la institucionalidad ordinaria.

En segundo lugar, la priorización es fundamental a la hora de establecer la destinación del gasto público debido a que las arcas estatales son limitadas y es necesario que se respeten derechos y principios fundamentales del ordenamiento jurídico, particularmente, la norma superior ordena que el gasto público social tenga preferencia sobre las demás asignaciones, porque busca el amparo de las necesidades básicas insatisfechas de la población, y en estados de excepción es todavía más evidente por cuanto las circunstancias excepcionales generan un mayor quebrantamiento de estas.

Por último, la legalidad del presupuesto supone que en tiempo de paz los únicos que pueden asignar gastos, hacer erogaciones o transferencias de crédito son los órganos de representación popular en virtud del principio democrático, sin embargo, esta regla general no es aplicable en estados de excepción porque el legislador extraordinario (Ejecutivo), dentro de la competencia que asume para atender la situación, tiene permitido realizar operaciones en este ámbito desde que tengan relación con las causas que generaron la crisis.

En lo relativo a las medidas sobre el gasto público decretadas en el marco de la emergencia económica, social y ecológica del Decreto 417 del 17 de marzo de 2020, se puede observar que el Gobierno nacional ha optado por una reorientación de los ingresos a los sectores que considera se han visto más afectados por la pandemia. El principal instrumento para este fin es el Fondo de Mitigación de Emergencias (FOME), administrado por el Ministerio de Hacienda y Crédito Público, al cual se le asignan grandes fuentes de financiamiento; sin embargo, no se precisan criterios objetivos de priorización que evidencien 
y aseguren la debida destinación de los recursos entre los más vulnerables, y, por tanto, no estaría acorde a la Constitución Política.

Por otro lado, se autoriza a las entidades territoriales cambiar el rumbo de las rentas con destinación específica de carácter legal para atender las consecuencias del covid-19. Otra respuesta fue fortalecer patrimonialmente el FNG con el objetivo de proteger el acceso a créditos de las personas naturales y jurídicas más afectadas, a través del respaldo de estos frente a las entidades financieras; empero, esta medida es inconstitucional porque solo se pudo entregar directamente a la entidad los recursos, y no cambiar la estructura de la Administración Pública.

En igual sentido, se creó la subcuenta para la Mitigación de Emergencias covid-19 en el Fondo Nacional de Gestión del Riesgo de Desastres; se estableció la adquisición obligatoria de títulos de Solidaridad (TSD) a los establecimientos de crédito; se permitió el otorgamiento de créditos a las Empresas de Servicios Públicos por parte de Findeter, que implementaron los pagos diferidos; se posibilitaron préstamos a Bancoldex por parte de Findeter para que financie proyectos relacionados con la crisis en sectores elegibles; se autorizó que los gobiernos territoriales puedan modificar el presupuesto según las necesidades de la pandemia, se financió el sistema de Transporte Masivo a través de créditos.

\section{Referencias}

Aristóteles (1988). Política. Gredos.

Banca de Desarrollo Territorial (2020). ¿Qué es Findeter? http://www.enticconfio.gov.co/

Cañón Ortegon, L. (2017). La solidaridad como fundamento del Estado social de derecho, de la seguridad social y la protección social en Colombia. Páginas de Seguridad Social, 1(1), 5-29. https://doi.org/10.18601/25390406.n1.01.

Fedesarrollo (2020). En Choque dual y posibles efectos sobre la economía colombiana. https://www.fedesarrollo.org.co/sites/default/files/DocumentosTrabajo/2020-03-26_choque_dual_y_posibles_efectos_sobre_la_economia_colombiana.pdf

Fernández Segado, F. (2012). La solidaridad como principio constitucional. Teoría y realidad constitucional, (30), 139-181. https://doi.org/10.5944/trc.30.2012.7004

Mora Restrepo, G. (2012). La solidaridad como principio y deber constitucional. Algunos desarrollos jurisprudenciales. Cuestiones de filosofía, (8), 41-58. https://revistas. uptc.edu.co/index.php/cuestiones_filosofia/article/view/613 
Piza Rodríguez, J. R. (Ed.) (2007). Curso de derecho presupuestario. Universidad Externado de Colombia.

Rojas Cabeza, A. (2013). Alcance y aplicación del concepto de gasto público social en el ordenamiento jurídico colombiano. DIXI, 17 (15), 43-54. https://doi.org/10.16925/ di.v15i17.638.

The World Bank (2020). The Economy in the time of Covid-19. World Bank. http://www. araujoibarra.com/wp-content/uploads/2020/04/The-Economy-in-the-Time-of-coVID-19.pdf

\section{Normatividad}

Congreso de la República de Colombia (1990). Ley 51 de 1990 de 28 de diciembre de 1990, Ley de operaciones de endeudamiento interno y externo de la nación.

Congreso de la República de Colombia (1991). Ley 7 de 1991 de 16 de enero de 1991, Ley marco de Comercio Exterior.

Congreso de la República de Colombia (1994). Ley 137 de 1994 de 2 de junio de 1994, Ley Estatutaria de Estados de Excepción.

Ministerio del Interior (2020). Decreto 457 de 22 de marzo de 2020.

Ministerio de Trabajo y Seguridad Social (1994). Decreto Ley 1295 de 1994. Sistema General de Riesgos Profesionales, 22 de junio de 1994.

Congreso de la República de Colombia (1999). Ley 546 de 23 de diciembre de 1999.

Congreso de la República de Colombia (1999). Ley 549 de 28 de diciembre de 1999.

Congreso de la República de Colombia (2012). Ley 1523 de 24 de abril de 2012, Política Nacional de Gestión de Riesgos de Desastre.

Congreso de la República de Colombia (2012). Ley 1530 de 2012 de 17 de mayo de 2012, Sistema General de Regalías.

Presidencia de la República de Colombia (1991). Constitución Política de Colombia.

Presidencia de la República de Colombia (1996). Decreto 111 de 1996 de 15 de enero de 1996, Estatuto Orgánico del Presupuesto. 
Presidencia de la República de Colombia (2020). Decreto Legislativo 417 de 17 de marzo de 2020 .

Presidencia de la República de Colombia (2020). Decreto Legislativo 444 de 21 de marzo de 2020.

Presidencia de la República de Colombia (2020). Decreto Legislativo 461 de 22 de marzo de 2020 .

Presidencia de la República de Colombia (2020). Decreto Legislativo 468 de 23 de marzo de 2020 .

Presidencia de la República de Colombia (2020). Decreto Legislativo 492 de 28 de marzo de 2020.

Presidencia de la República de Colombia (2020). Decreto Legislativo 517 de 4 de abril de 2020 .

Presidencia de la República de Colombia (2020). Decreto Legislativo 519 de 5 de abril de 2020 .

Presidencia de la República de Colombia (2020). Decreto Legislativo 522 de 6 de abril de 2020 .

Presidencia de la República de Colombia (2020). Decreto Legislativo 528 de 7 de abril de 2020 .

Presidencia de la República de Colombia (2020). Decreto Legislativo 529 de 15 de abril de 2020 .

Presidencia de la República de Colombia (2020). Decreto Legislativo 552 de 15 de abril de 2020 .

Presidencia de la República de Colombia (2020). Decreto Legislativo 559 de 15 de abril de 2020.

Presidencia de la República de Colombia (2020). Decreto Legislativo 562 de 15 de abril de 2020 .

Presidencia de la República de Colombia (2020). Decreto Legislativo 571 de 15 de abril de 2020 . 
Presidencia de la República de Colombia (2020). Decreto Legislativo 572 de 15 de abril de 2020 .

Presidencia de la República de Colombia (2020). Decreto Legislativo 575 de 15 de abril de 2020.

Presidencia de la República de Colombia (2020). Decreto Legislativo 581 de 15 de abril de 2020 .

Presidencia de la República de Colombia (2020). Decreto Reglamentario 685 de 2020.

\section{Jurisprudencia}

Corte Constitucional de Colombia, Sentencia C-015 de 23 de enero de 1996, M. P. José Gregorio Hernández Galindo.

Corte Constitucional de Colombia, Sentencia C-1046 de 4 de octubre de 2001, M. P. Eduardo Montealegre Lynett.

Corte Constitucional de Colombia, Sentencia C-160 de 3 de junio de 2020, M. P. Carlos Bernal Pulido.

Corte Constitucional de Colombia, Sentencia C-337 de 19 de agosto de 1993, M. P. Vladimiro Naranjo Mesa.

Corte Constitucional de Colombia, Sentencia C-434 de 12 de julio de 2017, M. P. Diana Fajardo Rivera.

Corte Constitucional de Colombia, Sentencia C-442 de 4 de mayo de 2001, M. P. Marco Gerardo Monroy.

Corte Constitucional de Colombia, Sentencia C-459 de 11 de mayo de 2004, M. P. Jaime Araújo Rentería.

Corte Constitucional de Colombia, Sentencia C-541 de 23 de noviembre de 1995, M. P. Jorge Arango Mejía.

Corte Constitucional de Colombia, Sentencia C-547 de 1 de diciembre de 1994, M. P. Carlos Gaviria Díaz. 
Corte Constitucional de Colombia, Sentencia C-685 de 5 de diciembre de 1996, M. P. Alejandro Martínez Caballero.

Corte Constitucional de Colombia, Sentencia C-700 de 18 de noviembre de 2015, M. P. Gloria Stella Ortiz Delgado.

Corte Constitucional de Colombia, Sentencia C-714 de 16 de julio de 2008, M. P. Nilson Pinilla Pinilla.

Corte Constitucional de Colombia, Sentencia C-767 de 16 de octubre de 2014, M. P. Jorge Ignacio Pretelt Chaljub.

Corte Constitucional de Colombia, Sentencia C-870 de 30 de septiembre de 2003, M. P. Jaime Araújo Rentería.

Corte Constitucional de Colombia, Sentencia T-125 de 14 de marzo de 1994, M. P. José Gregorio Hernández Galindo.

Corte Constitucional de Colombia, Sentencia T-152 de 14 de marzo de 1994, M. P. Eduardo Cifuentes Muñoz.

Corte Constitucional de Colombia, Sentencia T-413 de 28 de junio de 2017, M. P. Gloria Stella Ortiz Delgado.

Corte Constitucional de Colombia, Sentencia T-481 de 2 de mayo de 2000, M. P. José Gregorio Hernández Galindo.

Corte Constitucional de Colombia, Sentencia T-507 de 5 de julio de 2007, M. P. Marco Gerardo Monroy Cabra.

Corte Constitucional de Colombia, Sentencia T-517 de 7 de julio de 2006, M. P. Marco Gerardo Monroy Cabra.

Corte Constitucional de Colombia, Sentencia T-717 de 23 de agosto de 2006, M. P. Jaime Araújo Rentería.

\section{Comunicado de prensa}

Corte Constitucional de Colombia (2020). Comunicado de prensa No. 24.10 y 11 de junio de 2020. https://www.corteconstitucional.gov.co/comunicados/FIRMADO $\% 20$ Comunicado\%20No.pdf 
Corte Constitucional de Colombia (2020). Comunicado de prensa No. 25.17 y 18 de junio de 2020. https://www.corteconstitucional.gov.co/comunicados/Comunicado $\% 20$ No.\%2025\%20del\%2017\%20y\%2018\%20de\%20junio\%20de\%202020.pdf

Corte Constitucional de Colombia (2020). Comunicado de prensa No. 26.24 y 25 de junio de 2020. https://www.corteconstitucional.gov.co/comunicados/Comunicado\% 20 No.\%2026\%20del\%2024\%20y\%2025\%20de\%20junio\%20de\%202020.pdf

Corte Constitucional de Colombia (2020). Comunicado de prensa No. 27.1 y 2 de julio de 2020. https://www.corteconstitucional.gov.co/comunicados/Comunicado $\% 20$ No.\%2027\%20del\%201\%20y\%202\%20de\%20julio\%20de\%202020.pdf

Fecha de recepción: 5 de julio de 2020

Fecha de aprobación par 1: 13 de agosto de 2020

Fecha de aprobación par 2: 16 de julio de 2020 